\title{
Examining Social Commerce Intentions Through the Uses and Gratifications Theory
}

Gokhan Aydin, Istanbul Medipol University, Istanbul, Turkey

https://orcid.org/0000-0002-5652-8694

\begin{abstract}
Changes in consumer behavior enabled by social networking technologies is leading to a transformation in e-commerce. Consumers' use of social media sites and relevant technologies for different aspects of shopping has become an issue of utmost concern to retailers and related businesses. Adopting a uses and gratifications theory (UGT) perspective, the article aims to demonstrate motives of users utilizing social media in their purchase decisions. Drawing from digital marketing and e-commerce literature, relevant uses and gratifications for social commerce (s-commerce) were chosen as information access, escape, entertainment, passing time, cool and new trends, and socialization. The proposed model was analyzed and tested via OLS regression and ANOVA analysis using the data collected from a survey study on 361 subjects in Turkey. Information access, relaxing entertainment, and socialization motives emerged as significant antecedents of s-commerce intentions. No significant effect of demographics on social commerce intentions were observed in the analysis.
\end{abstract}

\section{KEYWORDS}

E-Commerce, S-Commerce, Social Commerce, Social Media, Social Networks, UGT, Uses and Gratifications

\section{INTRODUCTION}

Ease of access to information, products and services through Internet and information technologies, coupled with the rapid adoption of interactive technologies and social networks all over the world are transforming how business and commerce is conducted. As the number of users of social media sites such as Facebook, Twitter and Instagram grow, various businesses started using these platforms as an influential channel to reach and connect with potential and existing customers. Social networking sites can be leveraged to create trust and persuade consumers to choose products, however, control over the content published on these platforms is limited. To overcome these limitations e-commerce companies started providing opportunities to comment, appraise and share content on their own platforms to create an interactive environment for users that is alike to social media. This transition to Web 2.0, which facilitates interaction between users and organizations, and provides participation and sharing opportunities to its participants has led to the emergence of social commerce (s-commerce) concept in 2005. It has become a hot topic since then (Curty \& Zhang, 2011) and interest on it is expected to increase as it gains more significance (Chen \& Shen, 2015; Lin, Li, \& Wang, 2017). According to a systematic review of scholarly articles published between 2000 to 2014, "social media marketing", "online shopping \& e-commerce" are among the Top-10 topics of online marketing research (Roy, Datta, \& Basu, 2017). Two recent literature reviews on s-commerce that analyzed more than 100 and 400 studies respectively, stressed out the increasing significance of this concept (Busalim \& Hussin, 2016; Lin et al., 2017). This phenomenon is highlighted by the increasing number of articles-11 in 
2011 to 58 in 2016-appearing in Web of Knowledge database for "social commerce" or "s-commerce" terms in manuscript titles.

Social commerce (s-commerce) is considered as a new form of electronic commerce (e-commerce) which involves social networking systems that enable social interaction and user contributions (Liang, Ho, Li, \& Turban, 2011). A significant majority of the relevant literature accepts social commerce as the use of social media sites in various stages of consumer decision process and s-commerce activities act as an enabler of online purchase process (Shen, 2012).

S-commerce is expected to become one of the most widely adopted electronic commerce platforms in the not-so-distant future (Zhang and Benyoucef 2016). Social networking sites and relevant tools provide abundant opportunities to browse products and to get comments and reviews provided by real users and peers. Consequently, several companies have made efforts to get a firm foothold and carry out actual sales transactions over social media. For instance, Dell claimed that it made $\$ 6.5$ million by selling computers on Twitter between 2007 and 2010 and Disney allowed people to purchase tickets directly on Facebook without leaving the social network (Turban, Strauss, \& Lai, 2015, p. 12). Facebook, not so long ago, launched Facebook Marketplace, a platform that facilitates buying and selling of goods. Furthermore, Facebook owned Instagram expanded its "shoppable posts" feature, which provide brands the ability to add e-commerce links within their Instagram posts to help drive transactions, to nine countries (Instagram, 2018).

Companies practicing e-commerce, especially retailers, want to leverage the benefits of social media to a greater extent. For instance, Instagram and Pinterest-the more visually attractive social platforms- have enticed the interest of businesses and entrepreneurs. These platforms are utilized for promotion and marketing communications as well as directly selling products to users (Instagram, 2018). To exploit the opportunities offered by Web 2.0 and social networking systems, it is imperative to study and understand consumer motivations in these environments. Within this dynamic environment, the present study offers two major contributions to the s-commerce literature. From a theoretical perspective, a model based on a well-established theory on consumer motives in social media use, namely UGT is utilized to enhance the classical utilitarian \& hedonic motivation perspective that is used extensively in shopping literature. UGT is utilized by researchers in several context such as mobile app use behavior (Ha, Kim, Libaque-Saenz, Chang, \& Park, 2015), social media use behavior (Gan \& Li, 2018; Phua, Jin, \& Kim, 2017), and online shopping use behavior (Lim \& Ting, 2012) in addition to its original setting, mass media communications (Katz, Blumler, \& Gurevitch, 1974). Up till this study, UGT's application to social commerce is limited to only a few studies (Sharma \& Crossler, 2014; Yang \& Li, 2014). This theoretical approach provides a novel perspective at the s-commerce use behavior compared to extant literature as the general hedonic motives constructs utilized in relevant literature is somewhat limited compared to detailed sub-categories provided by UGT. From a managerial perspective, the major contribution is confirming/refuting transferability of existing knowledge on e-commerce to s-commerce. This research is carried out in a developing country, Turkey, situated at the crossroads of Asia and Europe with consumers influenced by both Western and Eastern cultural aspects. Given that prior research on s-commerce consumer motives in developing countries is scarce, testing for the relevance of each gratification in new settings is crucial to arrive at valid conclusions. In addition, the effect of demographics that are becoming less meaningful in explaining differences in technology adoption consumer behavior in developed countries may not reflect to developing markets well. Considering the differing properties of Turkish culture in terms of demographics, especially in gender equality and women's social status, may lead to conflicting results with the current trends in developed countries.

In line with the research gap, the following research questions are aimed to be answered with the present study:

Q1: How different type of motives/gratifications affect social commerce intentions?

Q2: Do major demographics (age, gender, education and income) affect social commerce intentions? 
Q3: Do major demographics (age, gender, education and income) affect user motivations/gratifications on social commerce intentions?

In order to answer the aforementioned research questions, e-commerce and s-commerce consumer behavior literature were examined. The research model was developed upon shopping values, UGT and relevant motivational studies. Hypotheses were developed and presented in Section 2, where the theoretical background is pondered in detail. This section is followed by methodology where sampling, data-collection and research model is described. In addition, operationalization of each relevant construct and the scales utilized are likewise presented in Section 3. Data analysis and results are provided in Section 4. The findings are discussed in Section 5 where theoretical and practical contributions of the present research are provided. The paper is concluded by highlighting the study's limitations and providing future research avenues.

\section{THEORETICAL BACKGROUND}

\subsection{Social Networking Sites \& Social Media}

Social network sites, social media and Web 2.0 has been used interchangeably in the literature. Derived from the categorization by Constantinides and Fountain (2008), basic categories of social media can be listed as follows: blogs \& microblogs (i.e. Wordpress, Blogger, Twitter), general social networking sites (i.e. Facebook), thematic and professional networking sites (i.e. Linked-in), content sharing sites \& communities (i.e. Flickr, Youtube, 5oopx), forums/bulletin boards, content aggregators, social bookmarking sites \& collaborative filtering sites (i.e. Stumbleupon or del.icio. us). As this categorization highlights, social networking sites are not limited to social media sites such as Facebook but encompass a wider range of sites such as forums, blogs, online communities and wikis. Consequently, use of social media in e-commerce / online shopping can be practiced in a wide-variety of platforms.

\subsection{Consumer Motives in Shopping and E-Commerce}

Consumer motives indicate the processes originated by needs aroused in an individual to achieve certain benefits or avoid unsought outcomes (Solomon, 2009). Human motives have been categorized in two basic categories, namely utilitarian and hedonic in consumer behavior literature (Hirschman \& Holbrook, 1982). Thus, basically consumers shop online or offline with task-focused utilitarian motives or hedonic experiential motives (Büttner, Florack, \& Göritz, 2013). These fundamental motives may be segmented into more detailed needs as well. Using various aspects of Web 2.0 technologies, e-commerce is becoming a medium that can provide hedonic experiences for consumers (Fang, George, Shao, \& Wen, 2016). The extant literature that focuses on motivations have considered several types of gratifications under a larger hedonic motivations context. Hedonic or experiential aspects of shopping include adventure seeking, pursuing new experiences, sensory stimulation, and escape from daily life and boredom. Essentially, these sub-dimensions of hedonic value are considered in a multi-faceted way in the Uses and Gratifications Theory leading us to adopt it to investigate social commerce consumer behavior in a detailed way.

\subsection{S-Commerce and E-Commerce}

The differing approaches to define and operationalize social commerce is evident in the extant literature. In one hand, there are transactional approaches that define social commerce as "use of social media for transactions and activities that are driven primarily by social interactions and user contributions" (Zhang et al. 2014; Liang et al. 2011). A similar perspective ties the definition of s-commerce to e-commerce and accepts it as a sub-category of e-commerce (Turban, Bolloju, \& Liang, 2010). Considering that e-commerce itself is defined in various ways (transactional-exchange 
of goods, services or a wider range of business activities including information exchange such as marketing, customer complaint management, supplier relations etc.), this perspective provides a broader range of operationalization that is not limited to transactions (Chaffey, 2009, p. 10; Turban et al., 2015). From a different point of view, s-commerce has been defined as "a form of Internet-based 'social media' that allow people to participate in the marketing and selling of products and services in online marketplaces and communities" (Stephen \& Toubia, 2010; Turban et al., 2015, p. 12). This approach highlights social media's role and the integration of social network features into internet retailers' systems. Thus, s-commerce can be considered as an evolution of Web 2.0 technologies to online commerce operations as well (Busalim \& Hussin, 2016; Turban \& Liang, 2011). Web 2.0 technologies provide increased interactivity and lead to higher participation of consumers in various stages of e-commerce by means of writing and sharing blogs, commenting or rating systems and similar tools. Given the wide range of social networking systems available to consumers that facilitate two-way communication, social commerce is not limited to general social media sites such as Facebook. Other platforms and tools including forums, ratings, reviews sites, recommendations on e-commerce platforms, blogs and others enable social commerce (Kucukcay \& Benyoucef, 2014). The majority of large e-commerce sites such as Amazon.com incorporate social networking tools (i.e. ratings, comment systems etc.) to their systems to enable social interaction within the system. Moreover, they are also offering new applications such as Spark by Amazon that aim users of sites such as Pinterest or Instagram that are becoming venues for shopping (Natanson, 2017).

\subsubsection{Social Commerce Intentions}

As discussed previously, s-commerce is defined in differing ways in the extant literature. It is usually considered as a type of electronic commerce activity (Turban \& Liang, 2011). However, considering the proliferated types of social networking sites and the variety of tools each utilize it is hard to arrive at a globally accepted definition. Within the context of this study s-commerce concept is basically operationalized as "the use of social media in buying process of consumers". Intention to use social commerce is termed as s-commerce intentions for convenience throughout this study. S-commerce intentions are revealed via questioning the users' tendency to follow / give online recommendations on social media and their intentions to use social media in their shopping decisions. Despite the rising interest in this concept, the underlying motivations that affect s-commerce are not clear as there are several relevant studies with contradictory conclusions. The differences in motivating factors as well as variables such as demographics are evident in the literature. An overview of the literature on demographics' effects on e-commerce and relevant technology adoption is provided in the following section.

\subsection{Uses and Gratifications}

To explore consumer motivations in online shopping and s-commerce in more detail, Uses and Gratifications Theory (UGT) is adopted in the present study. The classical utilitarian and hedonic value/motive framework is embraced from a wider perspective in UGT, a consumer-centric approach that was originally used to explain consumer motivations and effectiveness of mass-media use. According to UGT, "gratifications" are the perceived fulfillment of a need through an activity, for instance a particular media use. Consequently, UGT tries to explain and understand the psychological needs that are motivating individuals to use certain media and the resulting gratifications that fulfill these needs (Katz et al., 1974). In UGT, cognitive needs, affective needs, relaxation needs, personal and social integrative needs are considered as fundamental 'needs' categories. Similarly, to answer these basic needs, cognitive benefits, social-integrative benefits, personal-integrative benefits, and hedonic benefits are considered in the literature.

Cognitive gratifications or benefits, involve media's ability to deliver desirable information, whereas social integrative benefits indicate media's ability to enable social interaction and strengthening the consumer's ties with others. Personal integrative benefits are associated to the media's 
ability to enhance users' credibility, status, reputation and confidence. Finally, hedonic benefits refer to the aesthetic and pleasurable experiences obtained from using media (Katz, Blumler, \& Gurevitch, 1973; Nambisan \& Baron, 2007; Verhagen, Swen, Feldberg, \& Merikivi, 2015).

Albeit originating from mass communication use behavior, UGT is a well-established approach that has been utilized to examine consumer behavior in several contexts. In its early applications main gratifications identified for media use were related to entertainment and information. Recent studies using UGT on new communication media such as social media and mobile devices also have identified similar motives. Internet / website use (Eighmey \& McCord, 1998), mobile app use behavior (Ha et al., 2015), social media use behavior (Gan \& Li, 2018; Joinson, 2008; Phua et al., 2017), and online shopping behavior (Joines, Scherer, \& Scheufele, 2003; Lim \& Ting, 2012) are among relevant contemporary application areas that obtained similar conclusions. Intriguingly, UGT can be considered a more suitable theory to apply to social media than traditional media in our current environment. UGT assumes active participation of users and an intentional purpose in consuming/ using media. Unlike unwilling exposure to traditional media (outdoor, radio etc.) social media users willingly prefer and use these media (Ha et al., 2015; Xu, Ryan, Prybutok, \& Wen, 2012).

Studies based on UGT identified several gratifications that an individual achieves from using social media, resulted in gratifications relevant in s-commerce context (Yang \& Li, 2014). For instance, Papacharissi and Mendelson (2011)'s study on Facebook use behavior led to nine separate motives: information sharing, habitual pass time, relaxing entertainment, escapism, cool and new trend, companionship, professional advancement, social interaction and meeting new people. Other researchers have led to similar uses and gratifications of social media such as affection, coordination, disclosure, entertainment, escape, immediate access, relaxation, stylishness, leisure, social presence, following fashion, demonstrating sociability, and improving social knowledge (Papacharissi \& Mendelson, 2011; Phua et al., 2017; Smock, Ellison, Lampe, \& Wohn, 2011; Whiting \& Williams, 2013; Xu et al., 2012).

Among the many gratifications put forward in the extant social media and s-commerce literature, the following were selected as they cover basic needs and offer the balance between parsimony and enough depth to uncover relevant motives:

- Cognitive Needs: information seeking

- Affective/Hedonic Needs: escape, entertainment, passing time

- Social Needs: Socialization gratification, Cool / new trend

\subsubsection{Information}

Information related gratifications are the major cognitive gratification of using media according to UGT. From a shopping-value perspective, this is the major component that reflects the utilitarian motives. Information related motives are operationalized in several ways in the literature focusing on UGT such as information seeking, information access and information quality. This gratification is related to satisfying the users' apparent or latent information needs. Depending on the context, the users may seek the information himself/herself, it may be provided by mass media or provided on web pages / shopping sites. In an online context, the search for information is one of the major reasons Internet and websites are used for (Papacharissi \& Rubin, 2000; Peffers, 2001). In relevant studies on Internet use and e-commerce, seeking for and acquiring information was found to influence satisfaction of users (L. Chen, Gillenson, \& Sherrell, 2002; Joines et al., 2003; Song, Larose, Eastin, \& Lin, 2004). Likewise, obtaining information using social media sites is a cognitive gratification that was found to be among the main reasons to use social media (Hicks et al., 2012; Park, Kee, \& Valenzuela, 2009). Acquiring information shared and understanding what other people-especially of significance-think of is a value specific to virtual communities such as social media sites. A similar concept defining the behavior of consumers to browse products for collecting information on new fashion trends is called 
idea shopping (Bloch, Ridgway, \& Sherrell, 1989). Seeking information on fashion trends in itself is considered as a stand-alone gratification to browse products (Arnold \& Reynolds, 2003). Information seeking gratification that is operationalized in this study is defined as "acquiring information to help in commerce activities and buying decisions on social networking sites" (Yang \& Li, 2014). In the extant literature on social media use, information related gratifications were found to have a positive effect on relevant dependent variables such as use intentions (Bonds-Raacke \& Raacke, 2010; Ha et al., 2015; Park et al., 2009). In addition, it was found to be a significant motivation for using virtual communities and social commerce sites (Teo, Chan, Wei, \& Zhang, 2003; Yang \& Li, 2014) and engaging in e-commerce (Liu \& Forsythe, 2010).

In accordance with the established studies, information seeking gratification is hypothesized to have a positive effect on s-commerce intentions.

H1: Information seeking gratification will have positive effect on s-commerce intentions.

\subsubsection{Entertainment}

According to UGT, entertainment is one of the major factors that motivate users to use a particular media (Eighmey \& McCord, 1998; Luo, 2002) such as social media (Xu et al., 2012). Entertainment is a relevant motive in retail and shopping literature, generally considered as hedonic or experiential motives. Hedonic motives has become as significant as utilitarian motives in purchase decisions, moreover, shopping in itself is a means to create joy and to entertain oneself (Babin, Darden, \& Griffin, 1994; Childers, Carr, \& Carson, 2001). In online shopping, consumers enjoy the shopping process itself and shopping behavior in general is perceived as a fun activity as opposed to being a tedious task or job to be finished (To, Liao, \& Lin, 2007). Online shoppers pursue entertainment by using new technologies during online shopping (Kim \& Forsythe, 2007). Research focusing on social networking site and general internet use indicated that entertaining websites provide higher satisfaction (Luo, 2002) and the entertainment gratification is among the most significant factors affecting attitudes towards websites (Hausman \& Siekpe, 2009). Besides, it was also shown that entertainment affects users' participation behavior (Choi et al., 2016; Dholakia, Bagozzi, \& Pearo, 2004). Similarly, in studies on e-commerce, entertainment factor was found to have a positive effect on commercial-oriented media usage (Hicks et al., 2012; Lim \& Ting, 2012) and accepted as a significant predictor of behavior (Childers et al., 2001).

Based on extant literature, entertainment in social commerce context can be defined as "the extent to which the users perceive using social media for commerce as relaxing, fun and entertaining" (Hicks et al., 2012; Lim \& Ting, 2012). It was found to be a major motivation for using social commerce sites (Yang \& Li, 2014), therefore, we hypothesize entertainment gratification to have a positive effect on s-commerce intentions.

H2: Entertainment gratification will have positive effect on s-commerce intentions.

\subsubsection{Passing Time}

Internet and social media can be used in various ways. Social media, with its infinite scrolling, offers an effective way to utilize one's free time. The passing time gratification is grounded on this premise and can be defined simply as using social media to pass idle time. In several studies on social media, passing time gratification was found to be positively related to social media use behavior (Hicks et al., 2012; Sheldon, 2008). Consumers can see what their friends are using, buying, searching for and they can read and write relevant comments. Consequently, passing time gratification can be assumed to have a positive effect on s-commerce intention. The studies testing for this hypothesized effect found weak or insignificant effects. For instance passing time was found to be an insignificant predictor of social commerce in Yang and Li (2014)'s study but found to have a significant effect in certain 
others on social media (Hicks et al., 2012; Sheldon, 2008). Further studies in different contexts are needed to arrive at meaningful insights, thus we hypothesize pass time gratification to have a positive effect on s-commerce intentions.

H3: Passing Time gratification will have positive effect on s-commerce intentions.

\subsubsection{Escape}

Escape gratification is among the hedonic aspects of UGT and is considered to satisfy tension-free needs. Escape can be defined as participating in activities to get away from the real world, the problems and pressures of daily life (Xu et al., 2012). Considering that social media as a venue that promote easy communication, sharing and entertainment, it is an alternative to easily escape problems and pressures of daily life. However, studies incorporating escape gratification have led to contradicting results. Escape gratification was found to positively affect intentions and behavior in several studies on shopping and social media (Korgaonkar \& Wolin, 1999; Papacharissi \& Mendelson, 2011; Smock et al., 2011) whereas this effect was found to be insignificant in others (Xu et al., 2012; Yang \& $\mathrm{Li}, 2014)$. It should be noted that escapism have been considered under a larger "entertainment" or "hedonic motivation" construct in certain motivational studies on shopping (Hirschman \& Holbrook, 1982) and social media use (i.e. Ha et al., 2015; Smock et al., 2011). The limited number of studies that have incorporated this gratification separately limits the ability to justify the discrepancies. Therefore, to offer new evidence and test for the significance of this factor, escape gratification was hypothesized to have a positive effect on s-commerce intentions.

H4: Escape gratification will have positive effect on s-commerce intentions.

\subsubsection{Cool \& New Trend}

The relevant literature on UGT in social media reveal "cool and new trend" gratification as a possible factor affecting user behavior. This gratification rests upon the belief that individuals use new media and technologies because it is the thing to do and everybody else is doing it. This gratification points to the symbolic benefits of using media and technologies as a way to achieve and sustain social acceptance. For instance, two studies, one by Sheldon (2008) and the other by Papacharissi and Mendelson (2011) on motives for using Facebook found coolness and new trend among other factors to be a significant motive. Cool and new trend gratification in social commerce context refer to users utilizing social commerce to look cool and fashionable. Given that users perceive social commerce as a reasonably new trend, it is possible to feel cool benefiting from s-commerce (Sharma $\&$ Crossler, 2014). Therefore, we hypothesize cool and new trend gratification to have a positive effect on s-commerce intentions.

H5: Cool and new trend gratification will have positive effect on s-commerce intentions.

\subsubsection{Socialization}

Another matter of debate is the significance of the "social" aspect of s-commerce. Both social media and shopping have "social" aspects. Apart from utilitarian benefits or pure enjoyment purposes, shopping can be used as a way to socialize as well. This phenomenon of shoppers' desire for social interaction with others of similar interests, and affiliating with reference groups was proposed by Tauber (1972) and Reynolds and Beatty (1999) highlighted social needs in shopping environments. These needs are conceptualized as social shopping in a separate study (Arnold \& Reynolds, 2003). Consideration of social motives in e-commerce setting appeared in the form of a lack of socialization in early e-commerce operations that can deter consumers to shop online (Swaminathan, Lepkowska- 
White, \& Rao, 1999). However, with the emergence of mobile technologies and Web 2.0 technologies, online shopping has inherited a social aspect as well. Accordingly, social shopping began to act as a significant factor influencing user behavior on m-commerce and s-commerce contexts (Akesson, 2007; Parker \& Wang, 2016). Social media-in itself-derives value from the communication and interaction it provides to users. Consequently, social interaction is a natural element of social media sites. Meeting the expectations, the studies on social media resulted in the notion that people use social network sites for socializing in addition to other needs such as self-status seeking or entertainment gratifications (Park et al., 2009; Whiting \& Williams, 2013). It has been shown that social interactions on internet, whether they be on social media or websites, lead to higher engagement. For instance, it was found that social interaction motivation positively affects the time spent on a website (Ko, Cho, \& Roberts, 2005). Using Web 2.0 technologies and social networking sites, consumers are able to connect with others of similar interests. These ties created over virtual environments are posited to be influential in consumer behavior and purchasing decisions (Choi et al., 2016). Studies considering "social" dimension of social networking sites in shopping contexts such as "social capital theory" (Nahapiet \& Ghoshal, 1998) and "social identification" (Farivar, Turel, \& Yuan, 2018) social interaction (J. Huang \& Zhou, 2018) have led to conclusions that social interactions affect purchase intentions (i.e. L. T. Huang, 2016).

In the light of the studies on social media, e-commerce, and shopping value, we hypothesize socialization to have a positive effect on s-commerce intentions.

H6: Socialization gratification will have positive effect on s-commerce intentions.

\subsection{Effect of Demographics on Gratifications \& S-commerce}

The existing literature examining the effects of demographics on technology and information systems use suggests that differences exist with regards to age, gender and income (Morris \& Venkatesh, 2000). However, effect of demographics on use intentions were not covered in established consumer behavior theories and the lack of a well-founded framework presents a research gap. A summary of relevant studies on effect of demographics is provided in this section to offer insights on potential effects in social commerce setting.

The younger population have been exposed to Internet and social media at earlier ages and a digital divide between generations is evident in established studies on technology adoption (Korgaonkar \& Wolin, 1999; Pfeil, Arjan, \& Zaphiris, 2009; Viswanath Venkatesh \& Morris, 2000). It has been found that older users have lower perceived technological skills (Chung, Park, Wang, Fulk, \& McLaughlin, 2010) and lack of IT experience coupled with resistance to change creates barriers of adopting new technology and products (Trocchia \& Janda, 2000). Several studies have considered age as a significant factor that affects online shopping / e-commerce behavior (Bigné, Ruiz, \& Sanz, 2007; Hernández, Jiménez, \& José Martín, 2011; Liébana-Cabanillas \& Alonso-Dos-Santos, 2017; Stafford, Turan, \& Raisinghani, 2004). It should be noted that not all research yielded differences among age groups in shopping. Insignificant relationships in commerce related technology use (Dabholkar, Michelle Bobbitt, \& Lee, 2003; Hernández et al., 2011) or even negative relationships than expected (Joines et al., 2003) were also detected in shopping literature. This creates a research gap that further studies in differing contexts may shed light on.

Another significant demographic that is considered to have an effect on technology adoption and e-commerce use behavior is gender (Morris \& Venkatesh, 2000; Sun \& Zhang, 2006). It has been shown that behavioral intentions of men were affected to a greater extent by the usefulness of the technology than women (Venkatesh, Morris, and Ackerman 2000). Women, on the other hand, are more susceptible to external influence (i.e. social influence) than men (Haferkamp, Eimler, Papadakis, \& Kruck, 2012; Muscanell \& Guadagno, 2012; Sun \& Zhang, 2006). The gratifications of social media users was found to vary with depending on gender as well (Park et al., 2009). Effect of gender on 
online decision making and shopping behavior has also been an area that have attracted researchers' interest (Hernández et al., 2011; Lin, Featherman, Brooks, \& Hajli, 2018; Sun \& Zhang, 2006). According to Sheldon (2008), women are more likely use social media for entertainment purposes and maintaining existing relationships, whereas, men are after developing new relationships. Interestingly new methodologies pave way to predict gender based on the data obtained from e-commerce websites (Duong, Tan, \& Pham, 2016). Despite these findings, contradictory conclusions are present on gender's effect on technology use, media consumption and e-commerce. For instance, Nysveen, Pedersen, \& Thorbjørnsen, (2005)'s study on personal motives for media consumption and (Faqih \& Jaradat, 2015)'s study on mobile commerce indicated no differences between genders. The highly cited work of Venkatesh et al. (2000) demonstrated that medium to long-term decisions were not moderated by gender of users. It has been shown that if the respondents are familiar with the technology/service in question there are no significant differences between genders (Wong \& Hanafi, 2007). On the other hand, according to the Turkish Statistical Institute statistics, there is a gender imbalance among internet shoppers in Turkey. The percentage of males shopping online (34\%) are higher than that of females (25\%) (Turkish Statistical Institute, 2018). These phenomena indicate a research gap aimed to be explored by this study.

In addition to age and gender, income can be considered an important demographic in e-commerce and s-commerce settings as it affects the ability of the consumers to purchase. Consumers with higher income are faced with less perceived financial risk when shopping online compared to consumers with lower income. Consumers with lower income may not easily access e-commerce (including mobile or social commerce) or may not be as experienced as higher-incomed counterparts. Consequently, it may be considered as an enabler of or barrier to e-commerce (Hernández et al., 2011). It has been considered as a significant factor in relevant technology adoption such as mobile payment systems (Shin, 2009) and mobile commerce (Zhang, Zhu, and Liu 2012). Researchers considered income as a factor that affects shopping behavior (Miyazaki \& Fernandez, 2001; Valarezo, Pérez-Amaral, GarínMuñoz, Herguera García, \& López, 2018), yet not all findings are consistent. Income has been found as a significant factor affecting e-commerce use behavior (Valarezo et al., 2018) and its significance in emerging markets has been emphasized (Zhang et al., 2012). On the other hand, Bigné et al. (2007), Gibreel, AlOtaibi, and Altmann (2018) found no significant effect of income on mobile and social commerce intentions in their studies respectively.

Based on the findings in technology adoption and e-commerce literature, gender, age, education and income are accepted as major demographics that has potential effects on s-commerce intentions and gratifications, thus the following are hypothesized:

H7: Males will have higher social commerce intentions.

H8: Younger aged respondents will have higher s-commerce intentions.

H9: Higher education will lead to higher s-commerce intentions.

H10: Higher income will lead to higher s-commerce intentions.

H11: Females will have higher hedonic motives (entertainment, passing time, escape). whereas males will have higher cognitive (information) and social motives (socialization).

H12: Younger aged respondents will have higher hedonic motives (entertainment, passing time, escape) and social motives.

H13: Higher educated respondents will have higher cognitive motives (information) whereas lower educated people have higher hedonic motives.

\subsection{Context: Social Media Use in Turkey}

There are over 48 million Facebook accounts in Turkey, where more than 80 million people lives in a land on the intersection of Asia and Europe. This figure corresponds to nearly all the country's connected population, however due to multiple accounts, the number of unique users is estimated as 
34 million (Statista, 2017; We Are Social \& Hootsuite, 2017). Facebook is the second most popular site among internet users in Turkey after google.com in page views (IAB Turkey, 2017) and is the most popular social media site followed by Instagram and Twitter. The country, with its relatively young population is among the excessive users of the Internet and social media. Turkey is the $16^{\text {th }}$ country in terms of time spent online and 2.8 hours of each day is devoted to social media (We Are Social \& Hootsuite, 2017).

\section{METHODOLOGY}

The methodology in carrying out the present study is detailed in this section starting with the research model visualized in Figure 1, developed upon theoretical foundations. The model is followed by the sampling approach and measures employed in the study.

\subsection{Proposed Model}

Presented in Figure 1.

\subsection{Measures}

Each construct is designed by adapting existing scales of relevant studies. The gratifications are adapted from (Smock et al., 2011); socialization motivation from (Arnold \& Reynolds, 2003; Tauber, 1972) and social commerce intentions from (Zhang et al. 2014; Liang et al. 2011). The draft version of the questionnaire was reviewed by three marketing academicians to ensure ease of understanding and contextual relevance in Turkish language. Moreover, a pilot test with 28 students was conducted to fine-tune the questionnaire.

\subsection{Sampling \& Survey Administration}

The target population is the social networking site users who benefit from social media and social networking technologies in their purchasing decisions. This population is defined as the social commerce users in a more compact form. In order to test the aforementioned hypotheses, a survey study was conducted in Turkey. Convenience sampling and snow-ball sampling are used to reach potential respondents. The survey was seeded through the researcher's, his colleagues', acquaintances',

Figure 1. Proposed model

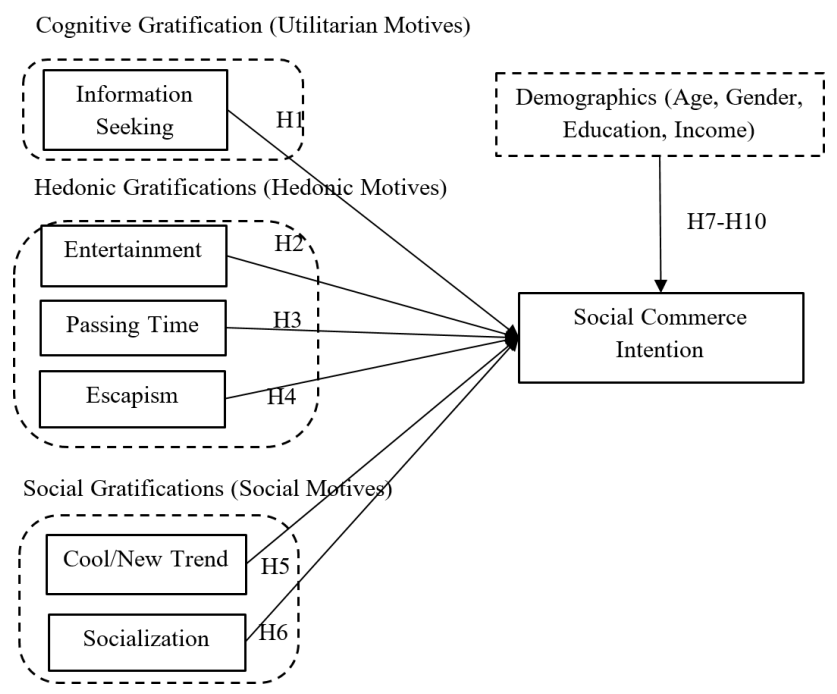


students' and ex-students' social media accounts (Facebook, LinkedIn and Twitter) and promoted in several online groups. Respondents of the questionnaire were asked to forward the questionnaire to a family member or friend who they believe may be interested in s-commerce activities. Participation in the survey was voluntary and the survey was kept online for two months during May and June 2017. Using two filter questions, one to validate social media use and the other to validate social media and relevant technologies use for shopping purposes, a total of 361 questionnaires were collected. The information on the total sample is provided in Table 1 and 2.

The information provided in Table 1 and Table 2 reveal that $91 \%$ of the respondents use social media actively. It should be noted that the nature of the survey was indicated beforehand to the potential respondents, so they were aware that study was on "social media". Among active users of social media, $42 \%$ specified that they use social media sites for periods longer than 3 hours each day. Moreover, $76 \%$ of active users indicated that they use social media in their purchases in several ways (looking for or reading product info or comments, doing actual transactions, etc.) $47 \%$ of the valid respondents were male and $25 \%$ of them held a master's or higher degree. The sample can be considered young, with almost half of the respondents aged within 18-21 bracket. Given the overall social commerce user details are unknown it is hard to get a representative sample. However, considering the profile of Internet users in Turkey, and Facebook \& Instagram user statistics, the obtained sample reflects the overall users in terms of gender and age but skewed towards higher earners (Turkish Statistical Institute, 2018). Social media use duration per day reflects the published social media use statistics in Turkey (We Are Social \& Hootsuite, 2017).

\section{DATA ANALYSIS AND RESULTS}

Out of the total sample, 268 usable questionnaires with full demographics information were obtained after accounting for filtering questions, non-complete and low-quality questionnaires. First of all,

Table 1. Sample demographics

\begin{tabular}{|c|c|c|c|c|c|c|c|}
\hline $\mathrm{N}=361$ & Frequency & $\%$ & Valid \% & & Frequency & $\%$ & Valid \% \\
\hline \multicolumn{4}{|c|}{ Monthly Income (USD equivalent) } & \multicolumn{4}{|c|}{ Education } \\
\hline$<400$ & 10 & 2.8 & 2.9 & High School or Less & 29 & 8.1 & 8.5 \\
\hline $401-800$ & 46 & 12.7 & 13.5 & College Degree & 46 & 12.7 & 13.5 \\
\hline $801-1200$ & 74 & 20.5 & 21.7 & University Student & 134 & 37.1 & 39.3 \\
\hline $1201-1600$ & 62 & 17.2 & 18.2 & University Degree & 51 & 14.1 & 15.0 \\
\hline $1601-2000$ & 39 & 10.8 & 11.4 & Master's + Degree & 86 & 23.8 & 25.2 \\
\hline $2001-2400$ & 33 & 9.1 & 9.7 & Missing & 15 & 4.2 & - \\
\hline $2401-2800$ & 25 & 6.9 & 7.3 & \multicolumn{4}{|l|}{ Age } \\
\hline $2801+$ & 52 & 14.4 & 15.2 & $18-21 y$ & 175 & 48.5 & 51.3 \\
\hline Missing & 20 & 5.5 & - & $22-25 y$ & 46 & 12.7 & 13.5 \\
\hline \multicolumn{4}{|l|}{ Gender } & $26-30 y$ & 28 & 7.8 & 8.2 \\
\hline Male & 162 & 44.9 & 46.8 & $31-39 y$ & 50 & 13.9 & 14.7 \\
\hline Female & 184 & 51.0 & 53.2 & $40-49$ & 33 & 9.1 & 9.7 \\
\hline \multirow[t]{2}{*}{ Missing } & 15 & 4.2 & - & $50 y+$ & 14 & 3.9 & 4.1 \\
\hline & & & & Missing & 15 & 4.2 & - \\
\hline TOTAL & 361 & 100 & & TOTAL & 361 & 100 & \\
\hline
\end{tabular}


Table 2. Sample SNS use info

\begin{tabular}{|c|c|c|c|c|}
\hline Using Social Media & Frequency & Percent & Valid \% & Cumulative \% \\
\hline Yes & 329 & 91.1 & 91.1 & 91.1 \\
\hline No & 32 & 8.9 & 8.9 & 100.0 \\
\hline \multicolumn{5}{|c|}{ Using Social Media for Shopping } \\
\hline Yes & 269 & 74.5 & 81.8 & 81.8 \\
\hline No & 60 & 16.6 & 18.2 & 100.0 \\
\hline Missing (No SNS Use) & 32 & 8.9 & - & - \\
\hline \multicolumn{5}{|l|}{ Social Media Use Per Day } \\
\hline$<1$ hour & 41 & 11.4 & 12.5 & 12.5 \\
\hline 1-2 hour & 84 & 23.3 & 25.5 & 38.0 \\
\hline 2-3 hour & 66 & 18.3 & 20.1 & 58.1 \\
\hline 3-4 hour & 59 & 16.3 & 17.9 & 76.0 \\
\hline 4-5 hour & 29 & 8.0 & 8.8 & 84.8 \\
\hline 5-6 hour & 23 & 6.4 & 7.0 & 91.8 \\
\hline $6+$ hours & 27 & 7.5 & 8.2 & 100.0 \\
\hline Missing & 32 & 8.9 & - & - \\
\hline Total & 361 & 100.0 & 100.0 & 100.0 \\
\hline
\end{tabular}

the collected data was sorted and analyzed in SPSS 22.0 software. Descriptive statistics (means, std. deviations and medians) are calculated and provided in Table 3.

Among the variables tested as the predecessors of social commerce intention, the lowest scores were attained for the cool and new trend gratification and the escapism gratification (avg. means of 1.79 and 2.31 on a 5-point scale). The significant majority ( $94 \%$ and $91 \%$ ) of the respondents answered the relevant questions in a negative or neutral way. Respondents answers to escapism gratification is similar to passing time gratification with an average mean score of 2.31 and $21 \%$ answering positively to the items in question. On the other hand, the highest scores are obtained in information seeking and entertainment factors (avg. means of 3.55 and 3.04 on a 5-point scale. Information seeking aspect of social commerce is perceived in a positive way by the $65 \%$ of the respondents ( $4 \& 5$ in 5 -point scale) followed by entertainment ( $41 \%$ answered positively). However, the respondents' disposition towards the social aspect of shopping operationalized under social shopping factor is not positive. About $28 \%$ of the respondents answered the items relevant to this factor positively ( $4 \& 5$ on a 5-point Likert scale) and the average score was 2.67 (out of 5). Finally, the descriptive statistics on the dependent factor reveal that social commerce intentions are neutral with differing views throughout the sample (avg. mean score: 3.12; st.dev.1.04). These findings are elaborated together with the regression analysis findings in the discussions section.

\subsection{Factor Analysis, Reliability \& Validity}

As a second step of the analysis, a confirmatory factor analysis was carried out and the resulting factor scores are used in a OLS regression analysis. Given that each question group is an established scale that has been previously validated in numerous studies, content and construct validity was considered to be supported. One item from socialization scale (SOC3) was left out of further analysis due to low factor loading. Composite reliability (CR) and Cronbach's alpha values were used to assess the internal consistency reliability of the model. The figures presented in Table 4 , are all above 0.7 let 
Table 3. Summary of scales and descriptive stats

\begin{tabular}{|l|l|l|l|l|l|l|l|}
\hline \multicolumn{1}{|c|}{ N=268 } & \multicolumn{1}{|c|}{ Mean } & \multicolumn{1}{|c|}{ Std. Dev. } & \multicolumn{1}{|c|}{ Median } & \multicolumn{1}{|c|}{ N=268 } & \multicolumn{1}{c|}{ Mean } & Std. Dev. & \multicolumn{1}{c|}{ Median } \\
\hline ESC1 & 2.27 & 1.108 & 2 & COL1 & 1.85 & .916 & 2 \\
\hline ESC2 & 2.29 & 1.148 & 2 & COL2 & 1.78 & .895 & 2 \\
\hline ESC3 & 2.37 & 1.111 & 2 & COL3 & 1.74 & .897 & 2 \\
\hline INF1 & 3.46 & 1.056 & 4 & INT1 & 3.03 & 1.070 & 3 \\
\hline INF2 & 3.45 & 1.080 & 4 & INT2 & 2.96 & 1.137 & 3 \\
\hline INF3 & 3.75 & .965 & 4 & INT3 & 3.12 & .966 & 3 \\
\hline REL1 & 3.06 & 1.033 & 3 & INT4 & 3.38 & .968 & 4 \\
\hline REL2 & 2.96 & 1.149 & 3 & SOC1 & 2.67 & 1.12 & 3 \\
\hline REL3 & 3.03 & 1.167 & 3 & SOC2 & 2.29 & 1.05 & 2 \\
\hline REL4 & 3.12 & 1.120 & 3 & SOC4 & 2.69 & 1.07 & 3 \\
\hline PAS1 & 2.07 & 1.018 & 2 & SOC5 & 3.09 & 1.17 & 3 \\
\hline PAS2 & 2.39 & 1.181 & 2 & SOC6 & 2.14 & .93 & 2 \\
\hline PAS3 & 2.72 & 1.278 & 3 & SOC7 & 3.16 & 1.07 & 3 \\
\hline
\end{tabular}

alone information seeking factor $(\alpha=0.65)$. The findings indicate the scales have acceptable reliability (Carmines \& Zeller, 1979; Fornell \& Larcker, 1981). To test for the discriminant validity, indicators' loadings on their own constructs were compared to the loadings on the other constructs (crossloadings). The cross-loadings were lower than items' loadings on their own constructs indicating discriminant validity. Convergent validity is evaluated using the outer loadings of the indicators and average variance extracted (AVE). The indicators' loadings on their own construct (outer loadings) were compared to loadings on other constructs (cross-loadings) to assess the discriminant validity. In addition, the square root of AVE was compared to the between-item-correlations (Fornell \& Larcker, 1981). As illustrated in Table 5, the inter-variable correlations were lower than the square root of AVE and AVE values were greater than 0.50 threshold. Consequently, the convergent and discriminant validity conditions are satisfied (Hair, Hult, Ringle, \& Sarstedt, 2013).

\subsection{Regression Analysis}

In this study, the effect of relevant uses and gratifications on social commerce intentions are evaluated using multiple regression analysis carried out in SPSS 22.0. The relationships between gratifications and social commerce intentions were tested utilizing the aforementioned hypotheses and the model presented as Equation (1).

$Y=\beta_{0}+X_{1} \cdot \beta_{1}+X_{2} \cdot \beta_{2}+X_{3} \cdot \beta_{3}+X_{4} \cdot \beta_{4}+X_{5} \cdot \beta_{5}+X_{6} \cdot \beta_{6}+\varepsilon$

$Y:$ Social commerce intention factor

$X_{1 \ldots 6}:$ Gratifications

$\beta_{m}:$ Regression coefficients

$\varepsilon:$ Error term 
Table 4. Factor analysis results

\begin{tabular}{|c|c|c|c|c|c|c|c|c|}
\hline Item & $\begin{array}{c}\text { Factor } \\
\text { Loading }\end{array}$ & $\begin{array}{l}\text { Variance } \\
\text { Explained }\end{array}$ & KMO & $\chi^{2}$ & $p<$ & Cronbach's $\alpha$ & AVE & CR \\
\hline ESC1 & .858 & \multirow{3}{*}{$81.91 \%$} & \multirow{3}{*}{.668} & \multirow{3}{*}{527.766} & \multirow{3}{*}{.0001} & \multirow{3}{*}{0.889} & \multirow{3}{*}{0.819} & \multirow{3}{*}{0.931} \\
\hline ESC2 & .952 & & & & & & & \\
\hline ESC3 & .903 & & & & & & & \\
\hline INF1 & .668 & \multirow{3}{*}{$59.62 \%$} & \multirow{3}{*}{.610} & \multirow{3}{*}{121.519} & \multirow{3}{*}{.0001} & \multirow{3}{*}{0.648} & \multirow{3}{*}{0.591} & \multirow{3}{*}{0.811} \\
\hline INF2 & .838 & & & & & & & \\
\hline INF3 & .790 & & & & & & & \\
\hline ENT1 & .703 & \multirow{4}{*}{$71.61 \%$} & \multirow{4}{*}{.789} & \multirow{4}{*}{584.771} & \multirow{4}{*}{.0001} & \multirow{4}{*}{0.867} & \multirow{4}{*}{0.716} & \multirow{4}{*}{0.926} \\
\hline ENT2 & .888 & & & & & & & \\
\hline ENT3 & .898 & & & & & & & \\
\hline ENT4 & .880 & & & & & & & \\
\hline PAS1 & .860 & \multirow{3}{*}{$81.12 \%$} & \multirow{3}{*}{.673} & \multirow{3}{*}{493.222} & \multirow{3}{*}{.0001} & \multirow{3}{*}{0.880} & \multirow{3}{*}{0.811} & \multirow{3}{*}{0.928} \\
\hline PAS2 & .947 & & & & & & & \\
\hline PAS3 & .893 & & & & & & & \\
\hline COL1 & .875 & \multirow{3}{*}{$82.54 \%$} & \multirow{3}{*}{.720} & \multirow{3}{*}{503.007} & & & & \\
\hline COL2 & .938 & & & & .0001 & 0.893 & 0.826 & 0.934 \\
\hline COL3 & .912 & & & & & & & \\
\hline SOC1 & .778 & & & & & & & \\
\hline SOC2 & ,718 & & & & & & & \\
\hline SOC4 & ,778 & & & & & & & \\
\hline SOC5 & .737 & $54.25 \%$ & .010 & 544.419 & .0001 & 0.830 & 0.543 & $0.8 / 1$ \\
\hline SOC6 & .662 & & & & & & & \\
\hline SOC7 & .741 & & & & & & & \\
\hline INT1 & .845 & & & & & & & \\
\hline INT2 & .648 & & & & & & & \\
\hline INT3 & .807 & 01.0510 & .174 & & .0001 & 0.110 & 0.011 & 0.001 \\
\hline INT4 & .811 & & & & & & & \\
\hline
\end{tabular}

The factor solutions for each variable explained variations ranging between $54-83 \%$; $\left(\mathrm{KMO}=0.610-0,816, \chi^{2} p<.0001\right)$.

The results of the regression analysis revealed in Table 5 led to the acceptance of three hypotheses (H1, H2, H5) yet rejection of three others (H3, H4, H6). No significant effect of passing time, cool $\&$ new trend or escapism on social commerce intentions were detected in the analysis. According to the calculated beta coefficients, the largest effect on social commerce intentions originated from entertainment gratification followed by socialization and information seeking respectively.

\subsection{Effect of Demographics: ANOVA and T-Tests}

ANOVA and t-tests were carried with social commerce intentions as dependent variable and basic demographics-age, gender, education and income-as independent variables. Firstly, the tests were carried out for gender ( 2 groups), income (8 groups) age (6 groups) and education (5 groups). Levene's test for equality of variances for each group indicated that the variances can be considered equal. No 
Table 5. Inter-variable correlations

\begin{tabular}{|l|l|l|l|l|l|l|l|}
\hline & \multicolumn{1}{|c|}{ SOC } & \multicolumn{1}{c|}{ ESC } & \multicolumn{1}{c|}{ INF } & \multicolumn{1}{c|}{ ENT } & \multicolumn{1}{c|}{ PAS } & COL & INT \\
\hline SOC & $\mathbf{. 7 3 7 *}$ & & & & & & \\
\hline ESC & .401 & $.907^{*}$ & & & & & \\
\hline INF & .358 & .295 & $.769 *$ & & & & \\
\hline ENT & .462 & .457 & .465 & $\mathbf{. 8 4 6} *$ & & & \\
\hline PAS & .349 & .427 & .339 & .544 & $\mathbf{. 9 0 1 *}$ & & \\
\hline COL & .378 & .424 & .246 & .303 & .492 & $\mathbf{. 9 0 8} *$ & \\
\hline INT & .361 & .242 & .317 & .370 & .183 & .181 & $\mathbf{. 7 8 2} *$ \\
\hline
\end{tabular}

* Square root of AVE is provided on the diagonal.

Table 6. Regression analysis results

\begin{tabular}{|l|l|l|l|l|l|l|}
\hline \multicolumn{1}{|c|}{ Factors } & \multicolumn{1}{c|}{ Beta } & \multicolumn{1}{c|}{ Std. Err } & \multicolumn{1}{c|}{ Std. Beta } & \multicolumn{1}{c|}{ t } & \multicolumn{1}{c|}{ p $<$} & \multicolumn{1}{c|}{ Hypothesis } \\
\hline (Constant) & $-5.69 \mathrm{E}-17$ & .055 & - & .000 & 1.000 & - \\
\hline Information & .149 & .064 & .149 & 2.337 & .020 & H1 - Accept \\
\hline Entertainment & .230 & .075 & .230 & 3.065 & .002 & H2 - Accept \\
\hline Passing Time & -.095 & .073 & -.095 & -1.305 & .193 & H3 - Reject \\
\hline Escape & .038 & .067 & .038 & .572 & .568 & H4 - Reject \\
\hline Cool \& New Trend & .026 & .067 & .026 & .387 & .699 & H5 - Reject \\
\hline Socialization & .210 & .066 & .210 & 3.165 & .002 & H6 - Accept \\
\hline
\end{tabular}

Adjusted $R^{2}: 0.205 ; F(6.262)=11.232, p<0.001$

differences were detected between genders (Women $\mathrm{M}=3.25$, $\mathrm{SD}=.79$; Men $\mathrm{M}=3.27, \mathrm{SD}=.69$ ), age $\left(\mathrm{F}(1,267)=0.260, p=.935\right.$, partial $\left.\eta^{2}=.005\right)$, income $\left(\mathrm{F}(1,267)=0.412, p=.895\right.$, partial $\eta^{2}$ $=.011)$ and education $\left(\mathrm{F}(1,267)=1.444, p=.249\right.$, partial $\left.\eta^{2}=.003\right)$ on social commerce intentions.

As a second step of this analysis, total sample was grouped into two in terms of age $(18-25 ; 26+)$, income ( $<1,200 \mathrm{USD} /$ month; $>1,201 \mathrm{USD}$ /month) and education (University graduate or above; high school degree or less) to provide easier interpretation and to increase the number of observations per group. A second round of "compare means" analysis (t-tests) was conducted with the demographics as grouping variables. Results indicated that there were no significant differences in social commerce intentions between income groups (Low $\mathrm{M}=3.21, \mathrm{SD}=.79$; High $\mathrm{M}=3.29, \mathrm{SD}=.70$ ), education groups (Low $\mathrm{M}=3.24 \mathrm{SD}=72$; High $\mathrm{M}=3,2979 \mathrm{SD}=0,77$ ) or age groups (Young $\mathrm{M}=3.24, \mathrm{SD}=.74$; Old $\mathrm{M}=3.29 \mathrm{SD}=.74)$. Further t-test were carried out to test for the effect of demographics on each of the gratifications and all the results are presented in Table 6.

The results led to the rejection of hypotheses $\mathrm{H} 7, \mathrm{H} 8, \mathrm{H} 9$ and $\mathrm{H} 10$.

According to the t-test results, only a minority of the tests led to significant differences between groups. No differences in gratifications were attained in terms of income or gender. On the other hand, significant differences were detected in socialization factor between lower and higher education groups (Low $\mathrm{M}=2.75 \mathrm{SD}=.72$; High $\mathrm{M}=2.47 \mathrm{SD}=0.80$ ) and younger and older age groups (Young $\mathrm{M}=2.76, \mathrm{SD}=.73$; Old $\mathrm{M}=2.42 \mathrm{SD}=.77$ ). Older sample perceived less socialization gratification compared to younger sample in social commerce. Moreover, higher educated sample perceived less socialization gratification. In addition, similar differences were detected in escapism gratification between lower and higher education groups (Low $\mathrm{M}=2.40 \mathrm{SD}=1.01$; High $\mathrm{M}=2.15 \mathrm{SD}=1.02$ ) and 
Table 7. T-tests based on demographic categories

\begin{tabular}{|c|c|c|c|c|c|c|c|c|c|c|c|c|}
\hline & Income & $\mathbf{N}$ & Mean & $\begin{array}{l}\text { Std. } \\
\text { Dev. }\end{array}$ & Sig. & $\begin{array}{c}\text { Mean } \\
\text { Diff. }\end{array}$ & Gender & $\mathbf{N}$ & Mean & $\begin{array}{l}\text { Std. } \\
\text { Dev. }\end{array}$ & Sig. & $\begin{array}{c}\text { Mean } \\
\text { Diff. }\end{array}$ \\
\hline \multirow{2}{*}{ SOC } & Low & 102 & 2.728 & 0.766 & \multirow{2}{*}{.175} & \multirow{2}{*}{.131} & Men & 124 & 2.720 & 0.801 & \multirow{2}{*}{.147} & \multirow{2}{*}{.135} \\
\hline & High & 164 & 2.598 & 0.761 & & & Women & 145 & 2.585 & 0.720 & & \\
\hline \multirow{2}{*}{ ESC } & Low & 102 & 2.235 & 1.013 & \multirow{2}{*}{.326} & \multirow{2}{*}{-.126} & Men & 124 & 2.371 & 1.051 & \multirow{2}{*}{.352} & \multirow{2}{*}{.116} \\
\hline & High & 164 & 2.362 & 1.023 & & & Women & 145 & 2.255 & 0.984 & & \\
\hline \multirow{2}{*}{ INF } & Low & 102 & 3.471 & 0.872 & \multirow{2}{*}{.154} & \multirow{2}{*}{-.143} & Men & 124 & 3.589 & 0.814 & \multirow{2}{*}{.522} & \multirow{2}{*}{.062} \\
\hline & High & 164 & 3.614 & 0.743 & & & Women & 145 & 3.526 & 0.775 & & \\
\hline \multirow{2}{*}{ REL } & Low & 102 & 3.076 & 1.002 & \multirow{2}{*}{.631} & \multirow{2}{*}{.058} & Men & 124 & 3.067 & 0.959 & \multirow{2}{*}{.704} & \multirow{2}{*}{.044} \\
\hline & High & 164 & 3.018 & 0.918 & & & Women & 145 & 3.022 & 0.937 & & \\
\hline \multirow{2}{*}{ COL } & Low & 102 & 1.837 & 0.882 & \multirow{2}{*}{.392} & \multirow{2}{*}{.089} & Men & 124 & 1.817 & 0.852 & \multirow{2}{*}{.591} & \multirow{2}{*}{.054} \\
\hline & High & 164 & 1.748 & 0.777 & & & Women & 145 & 1.763 & 0.793 & & \\
\hline \multirow{2}{*}{ INT } & Low & 102 & 3.208 & 0.789 & \multirow{2}{*}{.370} & \multirow{2}{*}{-.084} & Men & 124 & 3.242 & 0.795 & \multirow{2}{*}{.719} & \multirow{2}{*}{-.033} \\
\hline & High & 164 & 3.291 & 0.705 & & & Women & 145 & 3.274 & 0.686 & & \\
\hline Educ & & $\mathbf{N}$ & Mean & $\begin{array}{l}\text { Std. } \\
\text { Dev. }\end{array}$ & Sig. & $\begin{array}{l}\text { Mean } \\
\text { Diff. }\end{array}$ & Age & $\mathbf{N}$ & Mean & $\begin{array}{l}\text { Std. } \\
\text { Dev. }\end{array}$ & Sig. & $\begin{array}{l}\text { Mean } \\
\text { Diff. }\end{array}$ \\
\hline$S$ & Low & 172 & 2.751 & .722 & 003 & 285 & Younger & 183 & 2.756 & 0.730 & & \\
\hline 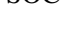 & Higher & 96 & 2.466 & .797 & .000 & .200 & Older & 86 & 2.417 & 0.774 & .001 & 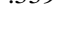 \\
\hline ESC & Low & 172 & 2.399 & 1.009 & & 2 & Younger & 183 & 2.393 & 1.011 & & \\
\hline Lace & Higher & 96 & 2.153 & 1.017 & ו & .240 & Older & 86 & 2.128 & 1.006 & . & .200 \\
\hline & Low & 172 & 3.578 & .771 & & & Younger & 183 & 3.568 & 0.768 & & \\
\hline 1171 & Higher & 96 & 3.517 & .838 & (.0נ & .000 & Older & 86 & 3.527 & 0.847 & .02 & (1) \\
\hline & Low & 172 & 3.094 & .964 & & & Younger & 183 & 3.090 & 0.941 & & \\
\hline NLL & Higher & 96 & 2.943 & .910 & .207 & .152 & Older & 86 & 2.942 & 0.952 & 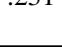 & .170 \\
\hline & Low & 172 & 1.806 & .802 & & & Younger & 183 & 1.798 & 0.793 & & \\
\hline 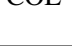 & Higher & 96 & 1.753 & .857 & .011 & .0Jנ & Older & 86 & 1.767 & 0.878 & 政 & (0) \\
\hline & Low & 172 & 3.241 & .720 & & & Younger & 183 & 3.244 & 0.737 & & \\
\hline 117 & Higher & 96 & 3.298 & .771 & דודם. & 1.007 & Older & 86 & 3.293 & 0.741 & .010 & .07 \\
\hline
\end{tabular}

younger and older age groups (Young $\mathrm{M}=2.39, \mathrm{SD}=1.01$; Old $\mathrm{M}=2.13 \mathrm{SD}=1.01$ ). Older sample has less escapism gratification compared to younger sample in social commerce. Similarly, higher educated sample has less escapism gratification. These results lead to the rejection of hypotheses H11 and partial acceptance of H12 and H13.

\subsection{Common Method Variance}

The concern for common method variance is addressed in the design and administration of the survey study. First of all, anonymity of respondents is assured, a simple language without technical terms and short questions are preferred. Additionally, it was indicated to the respondents that there are no correct or incorrect answers. The severity of the common method variance is than tested using Harman's single-factor test. The Harman's single-factor test result is calculated as 32\%. Variance explained by one factor solution is lower than $50 \%$ threshold indicating that common method variance is not a significant issue in the present study (Podsakoff, MacKenzie, Lee, \& Podsakoff, 2003). 


\section{DISCUSSIONS}

Findings suggest that both utilitarian and hedonic motivations in addition to socialization have significant effects on consumers' social commerce intentions. Namely, entertainment-a hedonic aspect-and the information seeking factor-a utilitarian gratification-emerged as significant factors affecting social commerce intentions.

The findings on basic descriptive statistics indicate that s-commerce is not perceived as a "cool and new trend" concept. It is evident that respondents are familiar with social media and its use in shopping and they do not perceive it as a novelty.

The finding that information seeking gratification, a utilitarian motive, have been found to affect social commerce intentions is in accordance with the extant literature. Whether it be on social media (Choi et al., 2016), mobile media (Aydin \& Karamehmet, 2017) or e-commerce setting (Close \& Kukar-Kinney, 2010) information provided by new technologies were deemed as a significant factor affecting intentions. However, not all the gratifications tested for their effects on social commerce intentions were found to be significant. The effect of two other hedonic gratifications-escapism and passing time-was found to be insignificant on social commerce intentions. In addition, the respondents scores to the relevant items indicate negative perceptions on these dimensions. S-commerce is not perceived as a tool to pass time and escape from daily life but as a general means to get entertained. The extant literature that have observed significant effects of these two constructs were on media usage (such as social media). These constructs-as aforementioned-highlight the opportunity provided by various media to easily get away from the burdens of daily life and use it to pass idle time. However, this ability of general media-and social media in particular-is not reflected to the social commerce context in the present study. Considering the nature of social commerce, actual purchase or browsing for purchase information requires more resources (time and /or money) and relevant desires that are to be satisfied. When using social media, users may not be interested in using this medium for shopping purposes to pass time or escape reality. There are probably better alternatives that suit the majority of users in differing ways to pass time. Using social media to pass idle time is a natural outcome of the new media (Hicks et al., 2012; Sheldon, 2008) but carrying out social commerce is not a necessity. The users can prefer watching entertaining content to get away from daily life. This premonition is confirmed in similar studies on e-commerce and s-commerce (Joines et al., 2003). In two recent studies on social commerce by Yang \& Li (2014) and Gan and Li (2018) in China found no significant effect of passing time or escape gratification on social commerce and social media use intentions respectively.

Unlike the studies that identified information related gratifications as the most significant factor for social media use (Hicks et al., 2012), entertainment emerged as the most important factor in the present study. This finding is consistent with findings of Yang and $\mathrm{Li}$ (2014) in social commerce setting and Lim and Ting (2012) on e-commerce. Entertainment is among the significant aspects of media use (Eighmey \& McCord, 1998; Luo, 2002; Xu et al., 2012) as well. Consequently, this outcome is in accordance with social media consumer behavior literature where similar constructs were found to affect use intentions (Gan \& Li, 2018; To et al., 2007). The entertainment factor was followed by socialization and information seeking factors in terms of the effect sizes (unstandardized beta coefficients) on social commerce intentions.

Socialization motivation emerged as one of significant motivating factors in practicing social commerce. This finding is parallel to studies such as Parker and Wang (2016) but contrasts certain others on online shopping (Anderson, Knight, Pookulangara, \& Josiam, 2014; Joines et al., 2003) and social media use (i.e. Gan \& Li, 2018). Socialization, which was lacking or limited in classical e-commerce and online shopping contexts, (Swaminathan et al., 1999) is becoming a valid factor affecting user behavior in more recent applications of e-commerce such as m-commerce and s-commerce (Åkesson, 2007; Parker \& Wang, 2016). Lack of extensive research to support or refute this finding is probably due to the operationalization of this factor under a larger "hedonic" 
or "experiential" motive construct in shopping literature (Anderson et al., 2014; i.e. Arnold \& Reynolds, 2003; Wolfinbarger \& Gilly, 2001). Nevertheless, it won't be wrong to propose that with the development of mobile technologies and Web 2.0 technologies, online shopping has inherited a social aspect as well. Accordingly, social motives began to act as a significant factor influencing user behavior on m-commerce and s-commerce contexts as also evidenced by (Åkesson, 2007; J. Huang $\&$ Zhou, 2018; Parker \& Wang, 2016) if not in traditional e-commerce contexts.

One of the objectives of this study has been to validate or refute that, consumer demographics (age, gender, education and income) have significance in explaining social commerce intentions. In contrast to particular studies on shopping behavior and online commerce (Liébana-Cabanillas \& Alonso-Dos-Santos, 2017; Sun \& Zhang, 2006; Valarezo et al., 2018), no significant effects of demographics were detected on social commerce intentions. This finding is parallel to findings of recent studies on e-commerce and shopping (Bigné et al., 2007; Faqih \& Jaradat, 2015; Gibreel et al., 2018; Hernández et al., 2011). Conflicting results observed in the literature regarding demographics such as income's significance may be related to differing cultures the studies were implemented in or how the s-commerce concept and use intentions were operationalized. Studies on actual transactionsbuying of goods/services over Internet/social media-may lead to significance of income as opposed to studies on intentions to use social media in shopping decision process.

A further analysis on demographics' effects on gratifications resulted in the finding that no effect of income or gender on each of the gratifications. On the other hand, significant differences were detected in socialization with regards age. Younger respondents were motivated less by socialization gratification compared to younger sample in social commerce. The lack of difference among younger and older sample indicates that regardless of age hedonic aspects motivate consumers in practicing social commerce.

The expected higher cognitive motive for higher educated group in terms of information gratification have not materialized according to the analysis results. Relatively high and low educated group both valued information aspects of s-commerce similarly. On the other hand, educated sample perceived less socialization gratification in s-commerce. Consequently, they are motivated to a lesser degree by the socialization offered through s-commerce.

\section{CONCLUSION}

This study contributes to the extant literature on social commerce, e-commerce and social media marketing in several ways. First of all, with few exceptions uses and gratification theory was not utilized in social commerce adequately. Secondly, s-commerce is defined in various ways and studies on this topic operationalize the relevant constructs in differing ways. This leads to a fragmentation and creates a need for further research that can provide comparable findings to accept/refute existing knowledge on online shopping behavior and e-commerce. Thirdly, the effect of demographics was found to vary in different cultures and contexts. It can even change for a particular context in the same culture in time as the underlying technology/service becomes more common and mainstream. Moreover, the particular context itself (social media and its tools) changes rapidly as the underlying systems evolve and algorithms and tools/services offered evolve.

Apart from theoretical contributions, the present study offers managerial implications for business owners, digital marketers and entrepreneurs vying to participate in social commerce. These implications are summarized in the following paragraphs.

No differences in social commerce intentions were detected in terms of gender, age, education or income. Given that all the data of participants used in analysis were obtained online and from social media users, at least a basic level of familiarity with the technology was already established. This may be counted among the major reasons of a lack of difference on demographics as indicated in the relevant studies (Venkatesh, Morris, and Ackerman 2000; Wong and Hanafi 2007). This leads to a significant conclusion for marketing practitioners that no easy segmentation can be made in 
terms of basic demographics (age, gender, education or income) to differentiate between users with differing s-commerce intentions. Alternatively, social commerce intentions may differ according to other constructs such as personality or lifestyle of the users. This suggestion should be tested in further studies.

Social media users that benefit from these mediums in their shopping process have not found this activity as cool or trendy. We can conclude that the novelty of social media and its use for online shopping is over. Users are motivated by other factors such as socialization, information seeking and hedonic aspects (i.e. entertainment) qualities offered by s-commerce. Digital / social marketing managers should focus on providing entertainment as a priority followed by easy access to information on their accounts and posts. The users' perceptions of entertainment gratification obtained by engaging in social commerce is neutral (3.06/5.00) but the variability is high. This leads to the conclusion that there are different segments among the users which find this activity entertaining and some not-so. The attitudes are not very strong and they can probably be swayed in either direction.

Perceptions on the information seeking benefit of using social media for shopping purposes is more positive compared to entertainment (3.55/5.00). The practitioners should continue providing informative content on their posts / platforms to cater to this gratification.

It was observed that social aspects of s-commerce affect motivations of younger consumers and less educated consumers more significantly. Companies targeting these demographic groups should take into account social aspects of commerce when developing/improving their systems.

Lastly, social interaction provided by the social networking sites and the social aspect of shopping should not be overlooked. This factor is found to affect social commerce intentions significantly as well. Offering tools offered by Web 2.0 technologies / social media on online commerce / shopping sites will be of benefit to the retailers. It should be noted that socialization gratification of s-commerce is perceived more positively by older sample compared to younger sample. Similarly, less-educated group perceived socialization gratification of s-commerce more positively.

\subsection{Limitations and Future Research}

This study is not without limitations. The conclusions that are drawn from the analyses are limited in several ways. First of all, the factors included in the model are not exhaustive as the buying process is a very complex phenomenon and there are numerous stimuli that affect decision-making (content, interaction, network characteristics, personality, lifestyles etc.). Second, the respondents were selected using a non-random sampling method, which is unfortunately the case in the majority of consumer behavior studies in literature.

A significant venue for further research is inclusion of further factors such as personality traits, lifestyles and working on a larger sample. In this way, it should be possible to carry out multigroup analysis to reveal different segments who value differing motives based on a wider range of personality traits. Moreover, a more representative sample may be obtained. Another research venue is carrying out a multi-cultural study to compare the social commerce motives in different cultures. Differences detected in user behavior and technology adoption between cultures may as well be evident in social commerce setting. Studies aiming to utilize clustering analysis based on social media use motivations and aforementioned factors may shed more light to differences in s-commerce intentions. As established in other studies certain users may be motivated by entertainment and others may be focused on carrying out s-commerce or other type of services provided by social media. 


\section{REFERENCES}

Åkesson, M. (2007). Value proposition in m-commerce: exploring service provider and user perceptions. Proceedings of 6th Annual Global Mobility Roundtable, 1-19. Retrieved from http://www.diva-portal.org/ smash/record.jsf?pid=diva2:239430

Anderson, K. C., Knight, D. K., Pookulangara, S., \& Josiam, B. (2014). Influence of hedonic and utilitarian motivations on retailer loyalty and purchase intention: A facebook perspective. Journal of Retailing and Consumer Services, 21(5), 773-779. doi:10.1016/j.jretconser.2014.05.007

Arnold, M. J., \& Reynolds, K. E. (2003). Hedonic shopping motivations. Journal of Retailing, 79(2), 77-95. doi:10.1016/S0022-4359(03)00007-1

Aydin, G., \& Karamehmet, B. (2017). A comparative study on attitudes towards SMS advertising and mobile application advertising. International Journal of Mobile Communications, 15(5), 514. doi:10.1504/ IJMC.2017.086366

Babin, B. J., Darden, W. R., \& Griffin, M. (1994). Work and/or Fun: Measuring Hedonic and Utilitarian Shopping Value. The Journal of Consumer Research, 20(4), 644. doi:10.1086/209376

Bigné, E., Ruiz, C., \& Sanz, S. (2007). Key Drivers of Mobile Commerce Adoption. An Exploratory Study of Spanish Mobile Users. Journal of Theoretical and Applied Electronic Commerce, 2(2), 48-60.

Bloch, P. H., Ridgway, N. M., \& Sherrell, D. L. (1989). Extending the concept of shopping: An investigation of browsing activity. Journal of the Academy of Marketing Science, 17(1), 13-21. doi:10.1007/BF02726349

Bonds-Raacke, J., \& Raacke, J. (2010). Myspace and facebook: Identifying dimensions of uses and gratifications for friend networking sites. Individual Differences Research, 8(1), 27-33.

Busalim, A. H., \& Hussin, A. R. C. (2016). Understanding social commerce: A systematic literature review and directions for further research. International Journal of Information Management, 36(6), 1075-1088. doi:10.1016/j.ijinfomgt.2016.06.005

Büttner, O. B., Florack, A., \& Göritz, A. S. (2013). Shopping Orientation and Mindsets: How Motivation Influences Consumer Information Processing During Shopping. Psychology and Marketing, 30(9), 779-793. doi:10.1002/mar.20645

Carmines, E. G., \& Zeller, R. A. (1979). Reliability and Validity Assessment. Beverly Hills, CA: Sage Publications. doi:10.4135/9781412985642

Chaffey, D. (2009). E-Business and E-Commerce Management: Strategy, Implementation and Practice (4th ed.). Essex, UK: Pearson Education Limited.

Chen, J., \& Shen, X. L. (2015). Consumers' decisions in social commerce context: An empirical investigation. Decision Support Systems, 79, 55-64. doi:10.1016/j.dss.2015.07.012

Chen, L., Gillenson, M. L., \& Sherrell, D. L. (2002). Enticing online consumers: An extended technology acceptance perspective. Information \& Management, 39(8), 705-719. doi:10.1016/S0378-7206(01)00127-6

Childers, T. L., Carr, C. L., \& Carson, S. (2001). Hedonic and utilitrian motivations for online retail shopping behavior. Journal of Retailing, 77(4), 511-535. doi:10.1016/S0022-4359(01)00056-2

Choi, E., Fowler, D., Goh, B., Yuan, J., Choi, E.-K., \& Wilson, K. (2016). Social Media Marketing: Applying the Uses and Gratifications Theory in the Hotel Industry companies toward improving their Facebook pages in order to meet the users' needs. Journal of Hospitality Marketing \& Management, 25(7), 771-796. doi:10.108 $0 / 19368623.2016 .1100102$

Chung, J. E., Park, N., Wang, H., Fulk, J., \& McLaughlin, M. (2010). Age differences in perceptions of online community participation among non-users: An extension of the Technology Acceptance Model. Online Interactivity: Role of Technology in Behavior Change, 26(6), 1674-1684. doi:10.1016/j.chb.2010.06.016

Close, A. G., \& Kukar-Kinney, M. (2010). Beyond buying: Motivations behind consumers' online shopping cart use. Journal of Business Research, 63(9-10), 986-992. doi:10.1016/j.jbusres.2009.01.022 
Constantinides, E., \& Fountain, S. J. (2008). Web 2.0: Conceptual foundations and marketing issues. Journal of Direct. Data and Digital Marketing Practice, 9(3), 231-244. doi:10.1057/palgrave.dddmp.4350098

Curty, R. G., \& Zhang, P. (2011). Social commerce: Looking back and forward. Proceedings of the American Society for Information Science and Technology, 48(1), 1-10. doi:10.1002/meet.2011.14504801096

Dabholkar, P. A., Michelle Bobbitt, L., \& Lee, E. (2003). Understanding consumer motivation and behavior related to self-scanning in retailing. International Journal of Service Industry Management, 14(1), 59-95. doi:10.1108/09564230310465994

Dholakia, U. M., Bagozzi, R. P., \& Pearo, L. K. (2004). A social influence model of consumer participation in network- and small-group-based virtual communities. International Journal of Research in Marketing, 21(3), 241-263. doi:10.1016/j.ijresmar.2003.12.004

Duong, D., Tan, H., \& Pham, S. (2016). Customer gender prediction based on E-commerce data. In Proceedings - 2016 8th International Conference on Knowledge and Systems Engineering, KSE 2016 (pp. 91-95). Academic Press. doi:10.1109/KSE.2016.7758035

Eighmey, J., \& McCord, L. (1998). Adding Value in the Information Age: Uses and Gratifications of Sites on the World Wide Web. Journal of Business Research, 41(97), 187-194. doi:10.1016/S0148-2963(97)00061-1

Fang, J., George, B., Shao, Y., \& Wen, C. (2016). Affective and cognitive factors influencing repeat buying in e-commerce. Electronic Commerce Research and Applications, 19, 44-55. doi:10.1016/j.elerap.2016.08.001

Faqih, K. M. S., \& Jaradat, M. I. R. M. (2015). Assessing the moderating effect of gender differences and individualism-collectivism at individual-level on the adoption of mobile commerce technology: TAM3 perspective. Journal of Retailing and Consumer Services, 22, 37-52. doi:10.1016/j.jretconser.2014.09.006

Farivar, S., Turel, O., \& Yuan, Y. (2018). Skewing users' rational risk considerations in social commerce: An empirical examination of the role of social identification. Information \& Management, 1-33. doi:10.1016/j. im.2018.05.008

Fornell, C., \& Larcker, D. F. (1981). Evaluating Structural Equation Models with Unobservable Variables and Measurement Error. JMR, Journal of Marketing Research, 18(1), 39-50. doi:10.1177/002224378101800104

Gan, C., \& Li, H. (2018). Understanding the effects of gratifications on the continuance intention to use WeChat in China: A perspective on uses and gratifications. Computers in Human Behavior, 78, 306-315. doi:10.1016/j. chb.2017.10.003

Gibreel, O., AlOtaibi, D. A., \& Altmann, J. (2018). Social commerce development in emerging markets. Electronic Commerce Research and Applications, 27, 152-162. doi:10.1016/j.elerap.2017.12.008

Ha, Y. W., Kim, J., Libaque-Saenz, C. F., Chang, Y., \& Park, M.-C. (2015). Use and gratifications of mobile SNSs: Facebook and KakaoTalk in Korea. Telematics and Informatics, 32(3), 425-438. doi:10.1016/j.tele.2014.10.006

Haferkamp, N., Eimler, S. C., Papadakis, A.-M., \& Kruck, J. V. (2012). Men Are from Mars, Women Are from Venus? Examining Gender Differences in Self-Presentation on Social Networking Sites. Cyberpsychology, Behavior, and Social Networking, 15(2), 91-98. doi:10.1089/cyber.2011.0151 PMID:22132897

Hair, J. F., Hult, G. T. M., Ringle, C. M., \& Sarstedt, M. (2013). A Primer on Partial Least Squares Structural Equation Modeling (PLS-SEM) (1st ed.). Thousand Oaks, CA: Sage Publications, Inc.

Hausman, A. V., \& Siekpe, J. S. (2009). The effect of web interface features on consumer online purchase intentions. Journal of Business Research, 62(1), 5-13. doi:10.1016/j.jbusres.2008.01.018

Hernández, B., Jiménez, J., \& José Martín, M. (2011). Age, gender and income: Do they really moderate online shopping behaviour? Online Information Review, 35(1), 113-133. doi:10.1108/14684521111113614

Hicks, A., Comp, S., Horovitz, J., Hovarter, M., Miki, M., \& Bevan, J. L. (2012). Why people use Yelp.com: An exploration of uses and gratifications. Computers in Human Behavior, 28(6), 2274-2279. doi:10.1016/j. chb.2012.06.034

Hirschman, E. C., \& Holbrook, M. B. (1982). Hedonic consumption: Emerging concepts, methods and propositions. Journal of Marketing, 46(3), 92-101. doi:10.1177/002224298204600314 
Huang, J., \& Zhou, L. (2018). Timing of web personalization in mobile shopping: A perspective from Uses and Gratifications Theory. Computers in Human Behavior, 88, 103-113. 10.1016/j.chb.2018.06.035

Huang, L. T. (2016). Flow and social capital theory in online impulse buying. Journal of Business Research, 69(6), 2277-2283. doi:10.1016/j.jbusres.2015.12.042

IAB Turkey. (2017). February 2017 Top 20 Lists. Retrieved July 7, 2015, from http://www.iabturkiye.org/sites/ default/files/internet_audience_toplist_02_2017.pdf

Instagram. (2018). Bringing shopping on Instagram to more countries. Retrieved March 22, 2018, from https:// business.instagram.com/blog/shopping-on-instagram-goes-global/

Joines, J. L., Scherer, C. W., \& Scheufele, D. A. (2003). Exploring motivations for consumer Web use and their implications for e-commerce. Journal of Consumer Marketing, 20(2), 90-108. doi:10.1108/07363760310464578

Joinson, A. N. (2008). Looking at, looking up or keeping up with people? In Proceeding of the twenty-sixth annual CHI conference on Human factors in computing systems - CHI '08 (p. 1027). New York: ACM Press. doi:10.1145/1357054.1357213

Katz, E., Blumler, J. G., \& Gurevitch, M. (1973). Uses and Gratifications Research. Public Opinion Quarterly, 37(4), 509. doi:10.1086/268109

Katz, E., Blumler, J. G., \& Gurevitch, M. (1974). Utilization of mass communication by the individual. In J. G. Blumler \& E. Katz (Eds.), The Uses of Mass Communication (pp. 19-32). Beverly Hills, CA: Sage Publication.

Kim, J., \& Forsythe, S. (2007). Hedonic usage of product virtualization technologies in online apparel shopping. International Journal of Retail \& Distribution Management, 35(6), 502-514. doi:10.1108/09590550710750368

Ko, H., Cho, C., \& Roberts, M. S. (2005). Internet uses and gratifications: A structural equation model of interactive advertising. Journal of Advertising, 34(2), 57-70. doi:10.1080/00913367.2005.10639191

Korgaonkar, P. K., \& Wolin, L. D. (1999). A multivariate analysis of Web usage. Journal of Advertising Research, 39(2), 53-68.

Kucukcay, I. E., \& Benyoucef, M. (2014). Mobile Social Commerce Implementation. In Proceedings of the 6th International Conference on Management of Emergent Digital EcoSystems - MEDES '14 (pp. 1-8). New York: ACM Press. doi:10.1145/2668260.2668276

Liang, T.-P., Ho, Y.-T., Li, Y.-W., \& Turban, E. (2011). What Drives Social Commerce: The Role of Social Support and Relationship Quality. International Journal of Electronic Commerce, 16(2), 69-90. doi:10.2753/ JEC1086-4415160204

Liébana-Cabanillas, F., \& Alonso-Dos-Santos, M. (2017). Factors that determine the adoption of Facebook commerce: The moderating effect of age. Journal of Engineering and Technology Management, 44, 1-18. 10.1016/j.jengtecman.2017.03.001

Lim, W. M., \& Ting, D. H. (2012). E-shopping: An analysis of the uses and gratifications theory. Modern Applied Science, 6(5), 48-63. doi:10.5539/mas.v6n5p48

Lin, X., Featherman, M., Brooks, S. L., \& Hajli, N. (2018). Exploring Gender Differences in Online Consumer Purchase Decision Making: An Online Product Presentation Perspective. Information Systems Frontiers. doi:10.1007/s10796-018-9831-1

Lin, X., Li, Y., \& Wang, X. (2017). Social commerce research: Definition, research themes and the trends. International Journal of Information Management, 37(3), 190-201. doi:10.1016/j.ijinfomgt.2016.06.006

Liu, C., \& Forsythe, S. (2010). Sustaining Online Shopping: Moderating Role of Online Shopping Motives. Journal of Internet Commerce, 9(2), 83-103. doi:10.1080/15332861.2010.503848

Luo, X. (2002). Uses and gratifications theory and e-consumer behaviors: A structural equation modeling study. Retrieved from http://jiad.org/vol2/no2/luo/

Miyazaki, A. D., \& Fernandez, A. (2001). Consumer Perceptions of Privacy and Security Risks for Online Shopping. The Journal of Consumer Affairs, 35(1), 27-44. doi:10.1111/j.1745-6606.2001.tb00101.x 
Morris, M. G., \& Venkatesh, V. (2000). Age Differences in Technology Adoption Decisions: Implications for a Changing Work Force. Personnel Psychology, 53(2), 375-403. doi:10.1111/j.1744-6570.2000.tb00206.x

Muscanell, N. L., \& Guadagno, R. E. (2012). Make new friends or keep the old: Gender and personality differences in social networking use. Computers in Human Behavior, 28(1), 107-112. doi:10.1016/j.chb.2011.08.016

Nahapiet, J., \& Ghoshal, S. (1998). Social Capital, Intellectual Capital, and the Organizational Advantage. Academy of Management Review, 23(2), 242-266. doi:10.5465/amr.1998.533225

Nambisan, S., \& Baron, R. A. (2007). Interactions in virtual customer environments: Implications for product support and customer relationship management. Journal of Interactive Marketing, 21(2), 42-62. doi:10.1002/ dir.20077

Natanson, E. (2017). Amazon Spark - A Social Network for Product Discovery. Forbes. Retrieved from https://www. forbes.com/sites/eladnatanson/2017/09/05/amazon-spark-a-social-network-for-product-discovery/\#14edd35791f9

Nysveen, H., Pedersen, P. E., \& Thorbjørnsen, H. (2005). Explaining intention to use mobile chat services: Moderating effects of gender. Journal of Consumer Marketing, 22(5), 247-256. doi:10.1108/07363760510611671

Papacharissi, Z., \& Mendelson, A. (2011). Toward a New(er) Sociability: Uses, Gratifications, and Social Capital on Facebook. In S. Papathanassopoulos (Ed.), Media Perspectives for the 21st Century (pp. 212-230). New York: Routledge. doi:10.4324/9780203834077

Papacharissi, Z., \& Rubin, A. M. (2000). Predictors of Internet Use. Journal of Broadcasting \& Electronic Media, 44(2), 175-196. doi:10.1207/s15506878jobem4402_2

Park, N., Kee, K. F., \& Valenzuela, S. (2009). Being Immersed in Social Networking Environment: Facebook Groups, Uses and Gratifications, and Social Outcomes. Cyberpsychology \& Behavior, 12(6), $729-733$. doi:10.1089/cpb.2009.0003 PMID:19619037

Parker, C. J., \& Wang, H. (2016). Examining hedonic and utilitarian motivations for m-commerce fashion retail app engagement. Journal of Fashion Marketing and Management: An International Journal, $20(4), 487-506$. doi:10.1108/JFMM-02-2016-0015

Peffers, K. (2001). The future of electronic commerce: A shift from the EC channel to strategic electronic commerce. Journal of Information Technology Theory and Application, 3(4), 7-16. Retrieved from http:// search.proquest.com/docview/200038024?accountid=8144\%5Cnhttp://sfx.aub.aau.dk/sfxaub?url_ver=Z39.882004\&rft_val_fmt=info:ofi/fmt:kev:mtx:journal\&genre=article\&sid=ProQ:ProQ\%3Aabiglobal\&atitle=The+ future+of+electronic+commerce $\% 3 \mathrm{~A}+\mathrm{A}+$ shift+from + the $+\mathrm{E}$

Pfeil, U., Arjan, R., \& Zaphiris, P. (2009). Age differences in online social networking - A study of user profiles and the social capital divide among teenagers and older users in MySpace. Computers in Human Behavior, 25(3), 643-654. doi:10.1016/j.chb.2008.08.015

Phua, J., Jin, S. V., \& Kim, J. (2017). Gratifications of using Facebook, Twitter, Instagram, or Snapchat to follow brands: The moderating effect of social comparison, trust, tie strength, and network homophily on brand identification, brand engagement, brand commitment, and membership intentio. Telematics and Informatics, 34(1), 412-424. doi:10.1016/j.tele.2016.06.004

Podsakoff, P. M., MacKenzie, S. B., Lee, J.-Y., \& Podsakoff, N. P. (2003). Common method biases in behavioral research: A critical review of the literature and recommended remedies. The Journal of Applied Psychology, 88(5), 879-903. doi:10.1037/0021-9010.88.5.879 PMID:14516251

Reynolds, K. E., \& Beatty, S. E. (1999). A relationship customer typology. Journal of Retailing, 75(4), 509-523. doi:10.1016/S0022-4359(99)00016-0

Roy, G., Datta, B., \& Basu, R. (2017). Trends and Future Directions in Online Marketing Research. Journal of Internet Commerce, 16(1), 1-31. doi:10.1080/15332861.2016.1258929

Sharma, S., \& Crossler, R. E. (2014). Intention to Engage in Social Commerce : Uses and Gratifications Approach. In Twentieth Americas Conference on Information Systems (Vol. 1, pp. 1-12). Retrieved from http://aisel.aisnet. org/cgi/viewcontent.cgi $?$ article $=1695 \&$ context $=$ amcis 2014

Sheldon, P. (2008). Student favorite: Facebook and motives for its uses. Southwestern Mass Communication Journal, 23(October), 39-53. doi:10.1080/03634520216511 
Shen, J. (2012). Social comparison, social presence, and enjoyment in the acceptance of social shopping websites. Journal of Electronic Commerce Research, 13, 198-212.

Shin, D.-H. (2009). Towards an understanding of the consumer acceptance of mobile wallet. Computers in Human Behavior, 25(6), 1343-1354. doi:10.1016/j.chb.2009.06.001

Smock, A. D., Ellison, N. B., Lampe, C., \& Wohn, D. Y. (2011). Facebook as a toolkit: A uses and gratification approach to unbundling feature use. Computers in Human Behavior, 27(6), 2322-2329. doi:10.1016/j. chb.2011.07.011

Solomon, M. R. (2009). Consumer behavior: Buying, having, and being. Upper Saddle River, NJ: PearsonPrentice Hall.

Song, I., Larose, R., Eastin, M. S., \& Lin, C. A. (2004). Internet Gratifications and Internet Addiction: On the Uses and Abuses of New Media. Cyberpsychology \& Behavior, 7(4), 384-394. doi:10.1089/cpb.2004.7.384 PMID:15331025

Stafford, T. F., Turan, A., \& Raisinghani, M. S. (2004). International and Cross-Cultural Influences on Online Shopping Behavior. Journal of Global Information Technology Management, 7(2), 70-87. doi:10.1080/10971 98X.2004.10856373

Statista. (2017). Forecast of social network user numbers in Turkey from 2014 to 2021. Retrieved July 7, 2017, from https://www.statista.com/statistics/569090/predicted-number-of-social-network-users-in-turkey/

Stephen, A. T., \& Toubia, O. (2010). Deriving Value from Social Commerce Networks. JMR, Journal of Marketing Research, 47(2), 215-228. doi:10.1509/jmkr.47.2.215

Sun, H., \& Zhang, P. (2006). The role of moderating factors in user technology acceptance. International Journal of Human-Computer Studies, 64(2), 53-78. doi:10.1016/j.jhcs.2005.04.013

Swaminathan, V., Lepkowska-White, E., \& Rao, B. P. (1999). Browsers or Buyers in Cyberspace? An Investigation of Factors Influencing Electronic Exchange. Journal of Computer-Mediated Communication, 5(2), 1-19. doi:10.1111/j.1083-6101.1999.tb00335.x

Tauber, E. M. (1972). Why Do People Shop? Journal of Marketing, 36(4), 46-49. doi:10.2307/1250426

Teo, H.-H., Chan, H.-C., Wei, K.-K., \& Zhang, Z. (2003). Evaluating information accessibility and community adaptivity features for sustaining virtual learning communities. International Journal of Human-Computer Studies, 59(5), 671-697. doi:10.1016/S1071-5819(03)00087-9

To, P. L., Liao, C., \& Lin, T. H. (2007). Shopping motivations on Internet: A study based on utilitarian and hedonic value. Technovation, 27(12), 774-787. doi:10.1016/j.technovation.2007.01.001

Trocchia, P. J., \& Janda, S. (2000). A phenomenological investigation of Internet usage among older individuals. Journal of Consumer Marketing, 17(7), 605-616. doi:10.1108/07363760010357804

Turban, E., Bolloju, N., \& Liang, T.-P. (2010). Social Commerce: An E-Commerce Perspective. In Proceedings of the 12th International Conference on Electronic Commerce: Roadmap for the Future of Electronic Business (pp. 33-42). Honolulu, HI: IEEE. doi:10.1145/2389376.2389382

Turban, E., \& Liang, T.-P. (2011). Introduction to the Special Issue Social Commerce: A Research Framework for Social Commerce. International Journal of Electronic Commerce, 16(2), 5-14. doi:10.2753/JEC10864415160201

Turban, E., Strauss, J., \& Lai, L. (2015). Social Commerce: Marketing, Technology and Management (pp. 1-37). Springer. doi:10.1007/978-3-319-17028-2_7

Turkish Statistical Institute. (2018). Household Information Technologies (IT) Use Research. Retrieved from http://www.tuik.gov.tr/PreHaberBultenleri.do?id=27819

Valarezo, Á., Pérez-Amaral, T., Garín-Muñoz, T., Herguera García, I., \& López, R. (2018, December). Drivers and barriers to cross-border e-commerce: Evidence from Spanish individual behavior. Telecommunications Policy, 1-10. 10.1016/j.telpol.2018.03.006 
Venkatesh, V., \& Morris, M. (2000). Why dont men ever stop to ask for directions? Gender, social influence, and their role in technology acceptance and usage behavior. Management Information Systems Quarterly, 24(1), 115-139. doi:10.2307/3250981

Venkatesh, V., Morris, M. G., \& Ackerman, P. L. (2000). A Longitudinal Field Investigation of Gender Differences in Individual Technology Adoption Decision Making Processes. Organizational Behavior and Human Decision Processes, 83(1), 33-60. doi:10.1006/obhd.2000.2896 PMID:10973782

Verhagen, T., Swen, E., Feldberg, F., \& Merikivi, J. (2015). Benefitting from virtual customer environments: An empirical study of customer engagement. Computers in Human Behavior, 48, 340-357. doi:10.1016/j. chb.2015.01.061

We Are Social \& Hootsuite. (2017). Digital in 2017 Global Overview: West Asia. Retrieved from https://www. slideshare.net/wearesocial/digital-in-2018-in-western-asia-part-1-northwest-86865983

Whiting, A., \& Williams, D. (2013). Why people use social media: A uses and gratifications approach. Qualitative Market Research, 16(4), 362-369. doi:10.1108/QMR-06-2013-0041

Wolfinbarger, M., \& Gilly, M. C. (2001). Shopping Online for Freedom, Control, and Fun. California Management Review, 43(2), 34-55. doi:10.2307/41166074

Wong, S. L., \& Hanafi, A. (2007). Gender Differences in Attitudes towards Information Technology among Malaysian Student Teachers: A Case Study at University Putra Malaysia. Journal of Educational Technology \& Society, 10(2), 158-169.

Xu, C., Ryan, S., Prybutok, V., \& Wen, C. (2012). It is not for fun: An examination of social network site usage. Information \& Management, 49(5), 210-217. doi:10.1016/j.im.2012.05.001

Yang, X., \& Li, G. (2014). Exploring social commerce adoption in China: A uses and gratification perspective. In International Conference on Management Science \& Engineering 21th Annual Conference Proceedings (pp. 546-554). Helsinki, Finland: IEEE. doi:10.1109/ICMSE.2014.6930277

Zhang, H., Lu, Y., Gupta, S., \& Zhao, L. (2014). What motivates customers to participate in social commerce? The impact of technological environments and virtual customer experiences. Information \& Management, 51(8), 1017-1030. doi:10.1016/j.im.2014.07.005

Zhang, K. Z. K., \& Benyoucef, M. (2016). Consumer behavior in social commerce: A literature review. Decision Support Systems, 86, 95-108. doi:10.1016/j.dss.2016.04.001

Zhang, L., Zhu, J., \& Liu, Q. (2012). A meta-analysis of mobile commerce adoption and the moderating effect of culture. Computers in Human Behavior, 28(5), 1902-1911. doi:10.1016/j.chb.2012.05.008 


\section{APPENDIX A. SCALES AND ITEMS}

\section{Table 8. Scales and items}

\begin{tabular}{|c|c|c|}
\hline Code & Item & Construct \& Source \\
\hline SOC1 & $\begin{array}{l}\text { I use social media in online shopping... (for all questions } \\
\text { below) } \\
\text { to shop online with others as a way to socialize. }\end{array}$ & \multirow{7}{*}{$\begin{array}{l}\text { Socializing } \\
\text { (Arnold \& Reynolds, } \\
\text { 2003; Tauber, 1972) }\end{array}$} \\
\hline SOC2 & .. to shop online with others having a social occasion. & \\
\hline SOC3 & $\begin{array}{l}\text { to shop online with others as a way to have a bonding } \\
\text { experience. }\end{array}$ & \\
\hline SOC4 & to shop online with others who have similar tastes/interests. & \\
\hline SOC5 & $\begin{array}{l}\text { to communicate with other people who share similar shopping } \\
\text { experiences. }\end{array}$ & \\
\hline SOC6 & $\begin{array}{l}\text { to achieve a sense of belonging by shopping for the same } \\
\text { products and brands that others purchase. }\end{array}$ & \\
\hline SOC7 & to observe what others are buying and using. & \\
\hline INT1 & $\begin{array}{l}\text { I will consider the shopping experiences of my friends on social } \\
\text { media when I want to shop. }\end{array}$ & \multirow{4}{*}{$\begin{array}{l}\text { Social Commerce } \\
\text { Intention } \\
\text { (Liang et al., 2011; } \\
\text { H. Zhang et al., } \\
\text { 2014) }\end{array}$} \\
\hline INT2 & $\begin{array}{l}\text { I will ask my friends on social media to provide me with their } \\
\text { suggestions before I go shopping. }\end{array}$ & \\
\hline INT3 & $\begin{array}{l}\text { I am willing to buy the products recommended by my friends on } \\
\text { social media }\end{array}$ & \\
\hline INT4 & $\begin{array}{l}\text { I intend to recommend shopping using social media to my } \\
\text { friends. }\end{array}$ & \\
\hline ESC1 & $\begin{array}{l}\text { I use social media in online shopping... (for all questions } \\
\text { below) } \\
\text { To eliminate pressures (or responsibilities). }\end{array}$ & \multirow{3}{*}{$\begin{array}{l}\text { Escape } \\
\text { (Smock et al., 2011) }\end{array}$} \\
\hline $\mathrm{ESC} 2$ & To forget about school, work, or other problems. & \\
\hline ESC3 & To get away from what I am doing. & \\
\hline INF1 & To seek useful information. & \multirow{3}{*}{$\begin{array}{l}\text { Information Seeking } \\
\text { (Yang \& Li, 2014) }\end{array}$} \\
\hline INF2 & To focus on fashion trends. & \\
\hline INF3 & To find favorable shops. & \\
\hline REL1 & Because it's interesting. & \multirow{4}{*}{$\begin{array}{l}\text { Entertainment } \\
\text { (Smock et al., 2011) }\end{array}$} \\
\hline REL2 & Because it is a pleasant rest. & \\
\hline REL3 & Because it relaxes me. & \\
\hline REL4 & Because it's enjoyable. & \\
\hline PAS1 & When I have nothing better to do. & \multirow{3}{*}{$\begin{array}{l}\text { Passing Time } \\
\text { (Smock et al., 2011) }\end{array}$} \\
\hline PAS2 & Because it gives me something to do to occupy my time. & \\
\hline PAS3 & Because it passes the time when I am bored. & \\
\hline COL1 & Because everybody else is doing it. & \multirow{3}{*}{$\begin{array}{l}\text { Cool and new trend } \\
\text { (Smock et al., 2011) }\end{array}$} \\
\hline COL2 & Because it is the thing to do. & \\
\hline COL3 & Because it is cool. & \\
\hline
\end{tabular}


Gökhan Aydın received his Ph.D. in Management Engineering from Istanbul Technical University in 2009. He worked for 12 years in marketing, sales and retail management departments in leading companies in Turkey. He is currently employed as an Assoc. Professor at Istanbul Medipol University. He is lecturing on various marketing classes in graduate and undergraduate programmes and his areas of interest include brand equity \& management and digital marketing (mobile, SNS, etc.). 